Reflexiones contables (Cúcuta)

40

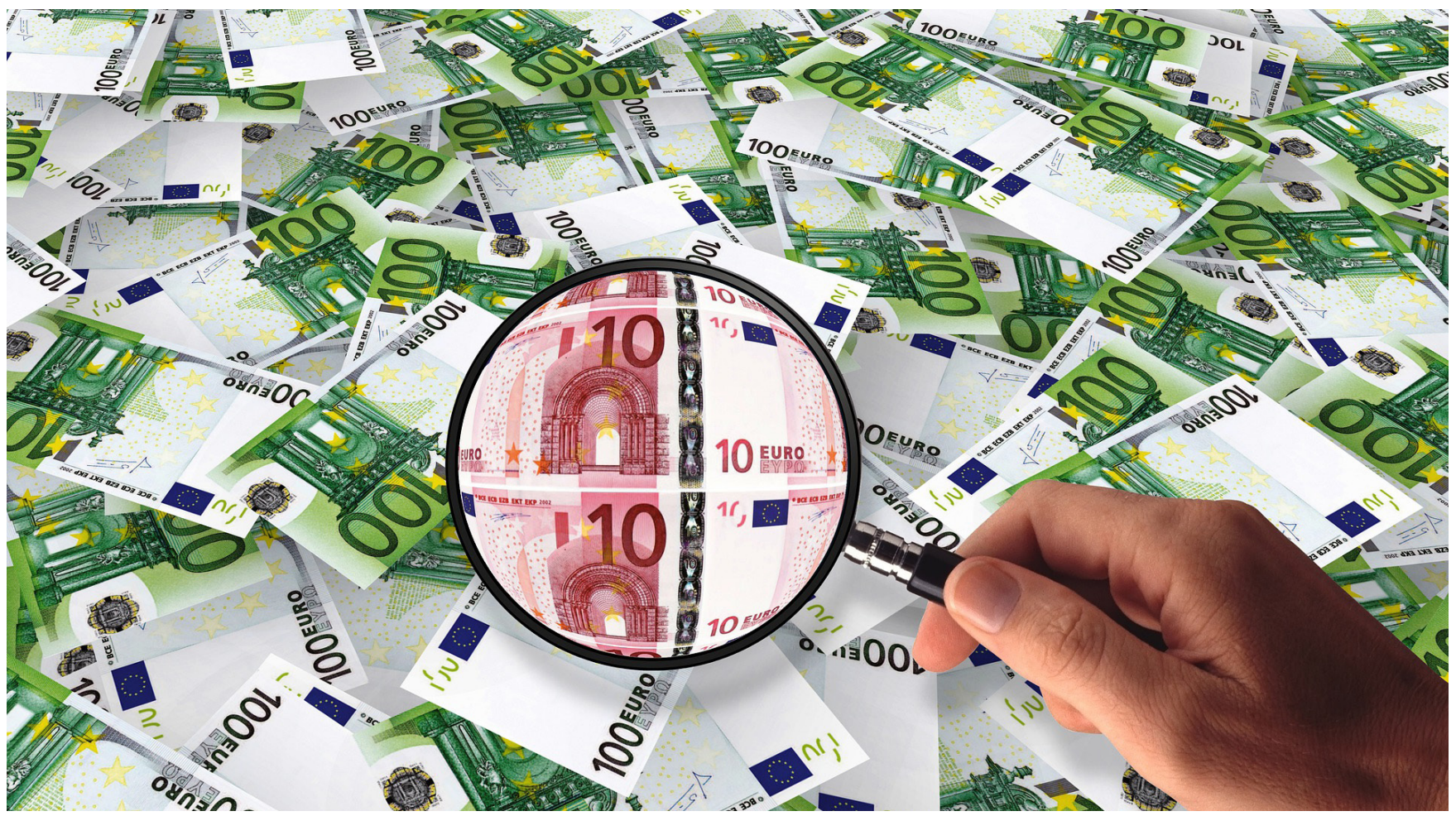

\title{
El contrabando insumos de confección de origen chino y su incidencia en la producción textil en la ciudad de Cúcuta
}

The contraband of inputs of confection of Chinese origin and its incidence in the textile production in the city of Cucuta

María Victoria Sánchez

Estudiante de modas, Mv_sanchez@fesc.edu.co,

Fundación de Estudios Superiores Comfanorte, Cúcuta,

Colombia
Ender José Barrientos-Monsalve

Doctor en Ciencias Gerenciales

Ej_barrientos@fesc.edu.co, Fundación de Estudios

Superiores Comfanorte, Cúcuta, Colombia 


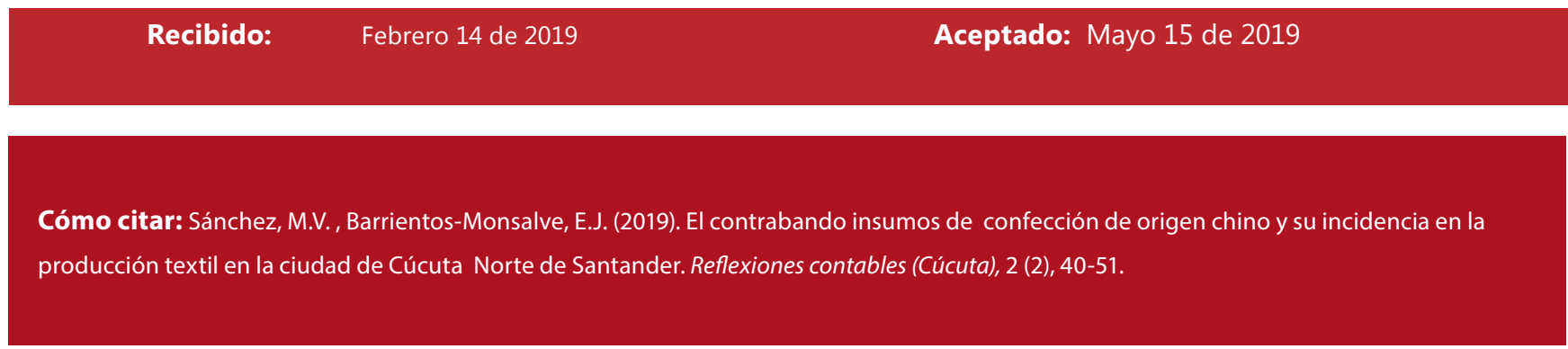

\section{Resumen}

El propósito de la investigación fue analizar el contrabando de insumos de confección de origen chino y la incidencia en la producción textil en la ciudad de Cúcuta, De esta manera bajo este escenario Colombia ha sido afectada por este comercio internacional de productos chinos, aparte que por medio del contrabando logran pasar mercancía sin declarar afectando la economía del productor local en la parte textil. La investigación tuvo como objetivo general Analizar la situación del contrabando textil en la ciudad de Cúcuta norte de Santander, y para poder dar respuesta a este objetivo se planteó una investigación con un enfoque cualitativo y un diseño de investigación de tipo documental descriptivo en donde se analizaron diferentes tipos de documentación sobre el área de estudio para poder establecer el análisis sobre el contexto en estudio, teniendo como resultado las diferentes consecuencias que trae el contrabando del comercio textil para la ciudad de Cúcuta.

Palabras clave: Contrabando, confección, producción textil.

\section{Abstract}

The purpose of the research was to analyze the smuggling of clothing consumables of Chinese origin and the incidence on textile production in the city of Cúcuta. Thus, under this scenario, Colombia has been affected by this international trade in Chinese products, apart from the fact that The smugglers manage to pass goods without declaring, affecting the economy of the local producer in the textile sector. The general objective of the research was to analyze the situation of textile smuggling in the city of Cúcuta, north of Santander, and in order to respond to this objective, a qualitative approach and a descriptive documentary research design were proposed. different types of documentation on the area of study to be able to establish the analysis on the context under study, resulting in the different consequences that contraband textile trade brings to the city of Cúcuta.

Keywords: Contraband, confection, textile production. 


\section{2}

\section{Introducción}

La economía textil siendo una de las más antiguas del mundo y posicionándose en todos los continentes como una de las principales acciones de intercambio económico donde establece que este tipo de economía basada en el rubro textil fue una de las primeras y una fuente de ingresos de muchas familias que impulsaron y crearon escenarios basados solo en ello, y usando unos conocimientos tecnológicos que para la época eran muy limitados pero al pasar el tiempo ya acercándose a la era actual esta netamente industrializada y fortaleciendo las relaciones económicas del mundo. Ya en la mayoría sino en todos los países se maneja la economía textil como una fuente constante de intercambios económicos que ayudan a mejorar los ingresos de las exportaciones e importaciones que realizan los diferentes países para cubrir las demandas de las sociedades teniendo como principal aporte la generación de empleos a nivel mundial.

A nivel mundial la industria textil constituye una importante fuente importante de ingresos en donde se generan una gran cantidad $d$ empleos contribuyendo así al producto interno bruto, en cifras según Angulo (2001),

...los ingresos y empleos para muchos países, en particular para países en desarrollo. Esta industria en el año 2001 representó el 2.5\% del comercio mundial de mercancías y el 3.3\% del comercio mundial de manufacturas. Según un análisis del clúster textil en Perú realizado por Angulo luna y miguel ángel Esta industria en el año 2001 representó el 2.5\% del comercio mundial de mercancías y el 3.3\% del comercio mundial de manufacturas(s/p).

Este rubro en el mundo presento números significativos para el mercado mundial aportando un 2,5\% del comercio mundial de mercancías, y esto hace favorito para lograr algún punto de vista del contrabando por la cantidad de dinero que establece este tipo de mercado, es por ello que el contrabando suele darse en productos controlados por monopolios estatales o más concretamente en aquellos fuertemente gravados fiscalmente, teniendo como resultado una gran diferencia entre el precio real y el precio final en los consumidores teniendo un margen muy beneficioso para organizaciones establecidas en el manejo de mercancías ilícitas.

Para los empresarios de Panamá está claro que es en Colombia donde se deben ejercer los controles para evitar el ingreso ilegal de mercancías, el dumping, la subfacturación y el lavado de dólares. Los empresarios son conscientes de que el control no se puede hacer con tratados bilaterales en los cuales Panamá perjudique su mayor fuente de ingresos, cuando esas prácticas son aceptadas por el comercio internacional.

Sin embargo, el comercio libre que para la República de Panamá compone una primacía que le reporta significativos ingresos ocasionó debilidades como perdidas en empresas textileras alrededor de 23 mil millones de pesos a las primeras, golpeadas por la revaluación del peso y la pérdida de más del 30 por ciento del mercado interno, como consecuencia del contrabando (Bedoya, 1994).

En Colombia un país integrante del continente latinoamericano sigue manejando el sector textil como uno de los que aportan al producto interno bruto, siendo un sector tradicionalmente fuerte entre los aportes económico que le ha dado a la nación, y ya alcanzando niveles óptimos de industrialización que mejoran cada día los procesos de estas industrias. Todas estas empresas surgen también de necesidades y de familias emprendedoras que vieron como futuro un escenario económico bajo un desarrollo constante, por su parte. (Achury 
y Bolívar, 2009) afirman que en Colombia, la industria textil se desarrolló entre una de las primeras industrias en Medellín en donde existió una tradición que se fue fortaleciendo y nacieron de empresas familiares teniendo muy baja nivel de producción y después se fueron uniendo para irse fortaleciendo y posicionarse a nivel nacional como una de las ciudades con mayor industrias textiles.

Según Moreno (2016), en un estudio realizado por la Superintendencia de Sociedades de Colombia, con información de la Cámara de Algodón, Fibras Textiles y Confecciones de la Asociación Nacional de Industriales (ANDI), existen cinco factores críticos que han afectado al sector: 1 . La caída de la demanda interna, 2. El contrabando, 3. La revaluación del peso y 4 . Altos Costos de producción. 5. Los efectos de la crisis del 2008 y su renacimiento en el 2012. Así mismo señala que en 2008, coincidieron varios elementos que crearon una situación complicada para este sector, la crisis financiera mundial que se presentó, permitió la caída de la demanda mundial; y países como Ecuador y Venezuela, quienes eran los principales socios comerciales de Colombia bloquearon sus puertas y se abrieron otras como EEUU y la unión Europea.

De la misma manera, en Norte de Santander también se sufre la crisis y los empresarios del sector textil principalmente de las telas en Cúcuta el contrabando, la crisis económica y otros factores sumados a los problemas de la frontera serán en una sola voz una oportunidad para llamar la atención del gobierno nacional en esta región.

Asimismo Caracol Cúcuta (2017), señala que los representantes del sector de los principales dueños de almacenes, expresaron su preocupación por el aumento en el cierre de negocios dedicados a la venta de este producto por la baja en ventas que afronta el gremio desde años atrás. "la situación está muy difícil y no sabemos qué hacer, en mi caso, no quiero despedir a nuestros empleados, pero si esto continua así, no tenemos otra opción" expresó, Melver Olivares, uno de los comerciantes de tela.

Agregó que el contrabando, está agudizando el panorama económico reflejado en las ventas "es un problema bastante serio porque hay actores del tejido social que acumularon cierta cantidad de dinero y que están acampando fuera del país y la única forma que ellos encuentran de mover los dineros es enviando textiles... acá ellos buscan personas desempleadas que les hacen el trabajo complementario de distribuir esas telas a un mercado negro que se mueve a nivel de pequeñas y medianas industrias y nosotros que generamos empleo, que pagamos industria comercio, impuesto que pagamos arriendo, estamos en cero".

La crisis que se afronta regionalmente crea una serie de consecuencias en la cual encontramos varios factores claves como lo cartera vencida, altos inventarios y falta de liquidez, lo afecta en el cierre de este año, únicamente y exclusivamente en las contrataciones de personal directo y talleres satélites que dejara de crear empresarios y obtendrá mayor desempleo y pobreza.

\section{Justificación}

La presente investigación se realizó aportando contenido epistemológico ante los escenarios del contrabando, teniendo un aporte significativo en el análisis documental de el contrabando textil en el norte de Santander, asimismo se presenta aportes prácticos por cuantos establece respuesta a situaciones de orden económico a causa de la realidad estudiada para entender estos escenarios y dar a conocer la situación actual.

En esta situación es indispensable que la industria textil tenga la habilidad de aprovechar sus fortalezas y superar sus debilidades para 


\section{4}

alcanzar un nivel de competitividad que le permita encarar al contrabando. Mediante este análisis tendremos la oportunidad de brindará al empresario y productor una mejor idea de la importancia de competitividad, cómo obtenerla y sobretodo sostenerla.

Mediante esta investigación se pretende que los empresarios y productores textileros y los consumidores tengan conocimiento de la capacidad que tienen las empresas para sobrepasar al contrabando, y que cada uno de ellos influya para que los productos provenientes de esta actividad ilícita pierdan presencia en el mercado.

\section{Objetivo general}

- Analizar la situación del contrabando textil en la ciudad de Cúcuta norte de Santander

\section{Objetivos Específicos.}

- diagnosticar la situación actual del contrabando de insumos textiles provenientes de china y su incidencia en la ciudad de Cúcuta norte de Santander.

- Estudia los factores que intervienen en el contrabando que afecta a la industria textil.

- Identificar la afectación del contrabando textil a las empresas manufactureras en la ciudad de Cúcuta norte de Santander

\section{Marco Teórico}

Para Moreno (2016), La industria textil en Colombia es una de las más representativas y tradicionales, se ha desarrollado por más de cien años pasando por la creatividad, innovación, representación empresarial, y transformando los escenarios productivos posicionándose a nivel mundial en este rubro. De la misma manera señala que para mediados de los años 60 la premisa era invertir en tecnología como el mejoramiento y adquisición de maquinaria para mejorar la producción, y en la década de 1980 se empezaron a establecer diferentes políticas para ingresar a la economía mundial y sobresalir en un contexto del rubro. Para Sectorial (2011), en su artículo Historia del negocio textil en Colombia, señala:

En 1987 se da la creación del Instituto para la Exportación y la Moda - Inexmoda, respondiendo a las necesidades de crear un organismo capaz de generar soluciones a las compañías del sector y que fuera una base para la internacionalización de la industria. Para 1989 nacen Colombiamoda y Colombiatex de las Américas, convirtiéndose en las principales ferias de la región y siendo la plataforma para el desarrollo de negocios e intercambio comercial de compañías del sector (s/p).

También señala que ante estos precedentes surgieron manifestaciones sobre relaciones comerciales internacionales para mejorar las economías emergentes de los diferentes países interesados basándose en el libre comercio teniendo como resultado los diferentes tratados como el Triángulo Norte (Guatemala, El Salvador y Honduras), Chile, Estados Unidos, Canadá, Unión Europea, Comunidad Andina (Bolivia, Ecuadory Perú); igualmente sobresalen preferencias arancelarias con Centroamérica y el Caribe. Finalmente, adicional de la importancia del relacionamiento internacional, el sector ha buscado su fortaleza interna a través de los Cluster y la inclusión en programas de transformación productiva.

\section{La innovación como determinante de competitividad en la industria textil- confección: el caso de corea y Colombia.}

En la investigación de Conde (2009), La innovación es uno de los factores de competitividad de mayor impacto en el mercado global actual. El sector textiles y confecciones colombiano, pese a ser uno de 
los de mayor crecimiento y representación en las exportaciones colombianas, debe estar diseñando permanentemente estrategias que apunten al aumento de su competitividad para mantenerse en el escenario internacional. El estudio de casos de desarrollo económico tardío exitoso como el de Corea, que potencia el sector textiles y confecciones en su estrategia de crecimiento, muestra alternativas ejemplares para aplicar a la industria de países en vías de desarrollo como Colombia. La investigación del contexto actual del mencionado sector en Colombia, a través de diversas fuentes como expertos, estadísticas y academia en conjunto con el estudio del caso Coreano, permite concluir algunas sugerencias y recomendaciones útiles para el crecimiento del sector textiles y confecciones teniendo en cuenta las innovación como herramienta clave de competitividad internacional.

La autora presenta también el Desarrollo económico: esta variable es entendida como un "proceso" de crecimiento económico pero con equitativa distribución de ingreso y generación de condiciones de bienestar general, algunos autores lo han identificado en una forma muy simple como variación en el PIB/población (per cápita), pero los agregados incluidos en el indicador de producción tienen importantes limitaciones como medida de bienestar, en una forma más amplia, lo identifica como un proceso multidimensional que considera reorganización y reorientación del sistema económico y social, lo que implica cambios no solo en ingreso y producto sino también en las estructuras institucionales, sociales y administrativas de un país. Desde la perspectiva de la innovación, varios autores han llegado a la conclusión de que es posible desarrollar la economía a través de innovaciones organizacionales, de proceso y de producto.

A su vez la autora presenta sobre Investigación y Desarrollo: Los informes señalan que apenas el 1 \% de la inversión mundial en investigación y desarrollo se dirige a los países latinoamericanos y está claro que sin investigación los países no pueden producir bienes de mayor valor agregado, que pueden ser exportados al resto del mundo a precios más altos. A menos que América latina entre en la carrera de la innovación, la mayoría de sus países estarán condenados a seguir exportando materias primas.

Para el caso colombiano, según la encuesta realizada por la Asociación Nacional de Empresarios de Colombia, ANDI citada por Conde (2009), el 55 por ciento de las compañías manifiesta tener centros o áreas de investigación y para su financiamiento destinan cerca del 2,2 por ciento de su presupuesto. Adicionalmente, Según el Global Competitiveness Report, citado por Conde (2009), Colombia fue ubicada en el puesto número 39 a nivel mundial en el tema de inversión en I+D la calificación fue de 3,4 (un punto por encima de la media) quedando por encima de países como: Chile, México, Argentina e Indonesia, entre otros. Por otro lado, se cuenta con instituciones como Colciencias que incentivan a personas y grupos de investigación para mostrar a Colombia como un país cada vez más competitivo e innovador frente al mundo.

\section{Comercio de productos de telas de fabricación China en Colombia}

Según Castellote (1994) en un artículo de diario el Tiempo, Los industriales de Corea y Japón solicitaron recientemente a sus gobiernos imponer también restricciones a las importaciones que están haciendo desde China, ante esta situación Colombia está en la misma dirección ya que está considerando unas medidas que acortaran las importaciones legales al contrabando de textiles y confecciones Chinas. 


\section{6}

Entre las políticas emanadas por el estado se pueden evidenciar el cobro de sobrearanceles, la creación de cuerpos especiales para trabajar en el contrabando, ya que las fuerzas policiales de Colombia están trabajando para incautan las mercancías detectadas a fin de quemarlas, venderlas o enviarlas devueltas a sus orígenes.

\section{Marco Metodológico}

La metodología, es el camino que conduce la realización de una investigación. Según Tamayo (2000), "Constituye la médula del plan; se refiere a la descripción de las unidades de análisis, o de investigación, las técnicas de recolección de datos, los Instrumentos y las técnicas de análisis." (p.113).

En la investigación realizada se presentó bajo un paradigma cualitativo y el diseño es documental con un nivel descriptivo. El presente trabajo de investigación pretende Investigar las realidades concernientes al contrabando del rubro textil en el Norte de Santander, en la ciudad de Cúcuta por medio de la información recogida de fuentes documentales.

Atendiendo a su naturaleza, se trata de una investigación de carácter descriptivo. A tal efecto, Tamayo y Tamayo (2002) caracteriza a este tipo de investigación como. "La descripción, registro, análisis e interpretación de la naturaleza actual, composición o procesos de los fenómenos. Trabaja sobre las realidades de los hechos y sus características fundamentales para presentar una interpretación correcta" (p.54).

Con esto se pretende establecer las relaciones causales del contrabando de telas en el Norte de Santander y poder establecer una descripción sobre los escenarios reales de esta situación.

\section{Resultados y análisis}


Contextualización documental.

Cuadro 01

\begin{tabular}{|c|c|c|}
\hline FUENTE & CONTENIDO & ANALISIS \\
\hline $\begin{array}{l}\text { El contrabando es una } \\
\text { enfermedad parn el sector } \\
\text { textil: Mincomereio. } \\
\text { CARACOL RADIO Medellin } \\
26 / 07 / 2017\end{array}$ & $\begin{array}{l}\text { Segiui el ministerio de } \\
\text { comercio. industria y } \\
\text { turismo, en este oftimo aflo } \\
\text { el país ha dejado de recibir } \\
\text { cerca de } 1 \text { billon de pesos y } \\
\text { se hart afectado uncs } 500 \\
\text { mil empleos debido al } \\
\text { impacto del contrabendo en } \\
\text { el sector textil colombianto. }\end{array}$ & $\begin{array}{l}\text { Colombia pasa por un tiempo } \\
\text { donde se ha generodo wan } \\
\text { problemśtica que afecta el sector } \\
\text { textil donde aun asi hay } \\
\text { incrutación de la DLAN por } \\
\text { productos ilegales sin marquillas } \\
\text { se es contante esa situación. }\end{array}$ \\
\hline $\begin{array}{l}\text { ¿Por qué el negocio textil } \\
\text { colombiano enfrenta su hora } \\
\text { más critica? Agosto 20, } \\
\text { 2017.El país. }\end{array}$ & $\begin{array}{l}\text { Las cifras aon } \\
\text { contundentes. } \\
\text { produccion de prendas da } \\
\text { vestir en Colombia tajo } 9,7 \\
\% \text { entre enera y junia de } \\
\text { eate ailo y la de productos } \\
\text { textiles, } 8,8 \% \text {. Hace un aflo } \\
\text { las cifras también estaban } \\
\text { en rojo, pero no de manera } \\
\text { tan alarmante. }\end{array}$ & $\begin{array}{l}\text { E1 contrabando ba generado } \\
\text { problemáticas importantes en el } \\
\text { pais y una de ellas es el } \\
\text { desempleo esto ha generado una } \\
\text { destrucrión de industria y aun } \\
\text { asi pobreza en rus empleados ya } \\
\text { que ha sido necesario despedir a } \\
\text { una cantidad grande para } \\
\text { zolventar un equilibrio } \\
\text { económico. }\end{array}$ \\
\hline $\begin{array}{l}\text { La crisis del seetor textil } \\
\text { POR: Mauricio cabrera } \\
\text { Galvis. AGOSTO } 22 \text { DE } \\
\text { 2017.EL TIEMPO }\end{array}$ & $\begin{array}{l}\text { Seguin el Dane, en juaio el } \\
\text { sector produjo } 20 \% \text { menos } \\
\text { que el mimo mes del aflo } \\
\text { pasado, mientras que en } \\
\text { confecciones el declive fuc } \\
\text { de } 13 \% \text {. }\end{array}$ & $\begin{array}{l}\text { la caida de la producción ha } \\
\text { generado un desempleo } \\
\text { considerable el cual las causas } \\
\text { de esta mal tierno en el sector } \\
\text { ha sido el dumping y } \\
\text { contrabando de inzumoe y aun } \\
\text { asi se le suma las importaciones } \\
\text { a tan bajo costo. }\end{array}$ \\
\hline $\begin{array}{lrr}\text { LA } & \text { RUTA } & \text { DEL } \\
\text { CONTRABANDO } & \text { DE } \\
\text { TEXTILES Por: } & \text { Claudia }\end{array}$ & $\begin{array}{l}\text { ¿Cómo y por dónde entran } \\
\text { las mercancias que tanto } \\
\text { daño han cousado a los }\end{array}$ & $\begin{array}{l}\text { Colombia dobe ejercer max } \\
\text { controles en tres aspectos } \\
\text { generales que son el Domping la }\end{array}$ \\
\hline
\end{tabular}




\begin{tabular}{|c|c|c|}
\hline $\begin{array}{l}\text { Bedoya Madrid } 13 \text { de } \\
\text { noviembre de } 1994 . E L \\
\text { TIEMIPO }\end{array}$ & $\begin{array}{l}\text { textileros y confeccionistas } \\
\text { colombianos? Según los } \\
\text { reeultados de una } \\
\text { investigación crdenada por } \\
\text { los mismos textileros, } \\
\text { Panamá y av zona libre de } \\
\text { Colóti es el puente para el } \\
\text { ingreso ilegal de telas y } \\
\text { confecciones. }\end{array}$ & $\begin{array}{l}\text { subfacturación y el lavado de } \\
\text { dólares que ha generado una } \\
\text { gran complicidad para hacer } \\
\text { tanto dazio al sector textil } \\
\text { generando la gran problemática } \\
\text { que ea el contrabando. }\end{array}$ \\
\hline $\begin{array}{l}\text { El sector textil en Colombia: } \\
\text { ¿Cómo ser más competitivos? } \\
\text { Campos, A. G. (2014). } \\
\text { (Ensnyo especialización en } \\
\text { gereneia en comereio } \\
\text { internacional).Bogota, } \\
\text { Colombia. }\end{array}$ & $\begin{array}{l}\text { La industria textil es uno de } \\
\text { mayor desarrollo en el } \\
\text { mercado internacional. El } \\
\text { sector textil colombiano, } \\
\text { pese a aer uno de los de } \\
\text { mayor crecimiento en las } \\
\text { exportaciones colombianas, } \\
\text { ha tenido un periodo de } \\
\text { crisis, que se debe } \\
\text { principolmente a la falta de } \\
\text { preparación para aumir los } \\
\text { setos de la apertura } \\
\text { económica, es por ello que } \\
\text { el aistema productivo textil } \\
\text { debe } \\
\text { permanentemente politicas } \\
\text { qua apunten al aumento de } \\
\text { su competitividad para } \\
\text { mantenerse en el escenario } \\
\text { internacional. }\end{array}$ & 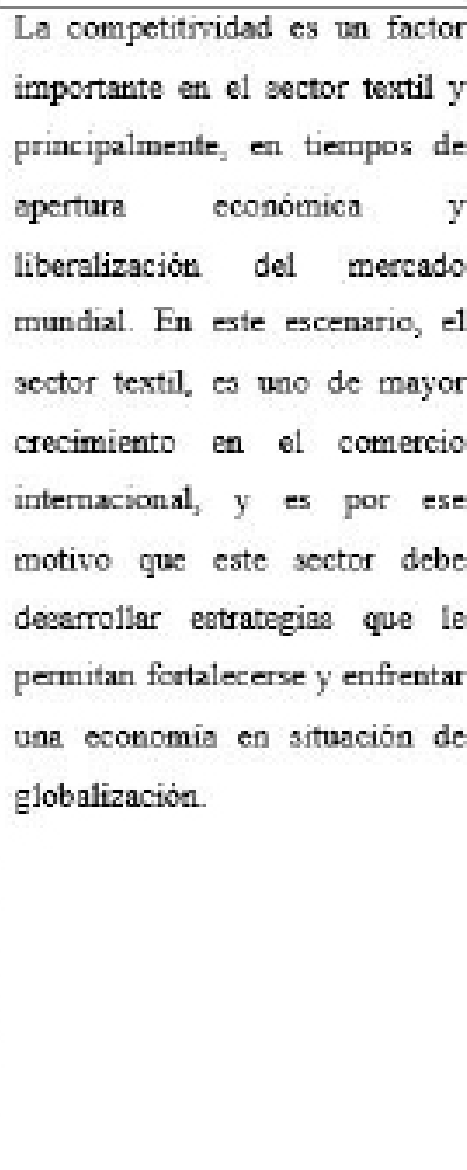 \\
\hline $\begin{array}{l}\text { El hilo está que se rompe en el } \\
\text { sector textil confecciones. Por: } \\
\text { Fredy Carrera, Septiembre } \\
28, \quad 2017 . \text { Conffdencial }\end{array}$ & $\begin{array}{l}\text { Efecto que se ha visto en lo } \\
\text { que va de este } 2017 \text { en } \\
\text { donde se han perdido } \\
\text { alrededor de } 50 \text { mil }\end{array}$ & $\begin{array}{l}\text { Los textileros extín afrcntando } \\
\text { una problemática grave la cual } \\
\text { se ven afectados principalmente } \\
\text { sus empleados ya que se ha }\end{array}$ \\
\hline
\end{tabular}




\begin{tabular}{|c|c|c|}
\hline Colombia. & $\begin{array}{l}\text { empleos y cuya } \\
\text { productivided se mantiene } \\
\text { en cifras negativas como lo } \\
\text { demuestran datos del Dane. }\end{array}$ & $\begin{array}{l}\text { generado una gran cantidad de } \\
\text { desempleos lo cual genera una } \\
\text { productividad mala para cada } \\
\text { una de las empresas y una mala } \\
\text { recha económica de los } \\
\text { empresarios del sector textil. }\end{array}$ \\
\hline $\begin{array}{l}\text { El sector textll lidera las eifras } \\
\text { del contrabando en Colombia } \\
\text { Por Tamara Gonzalez Litman } \\
\text { - } \mathbf{2 3} \text { de agosto de } \mathbf{2 0 1 7} \text {. }\end{array}$ & 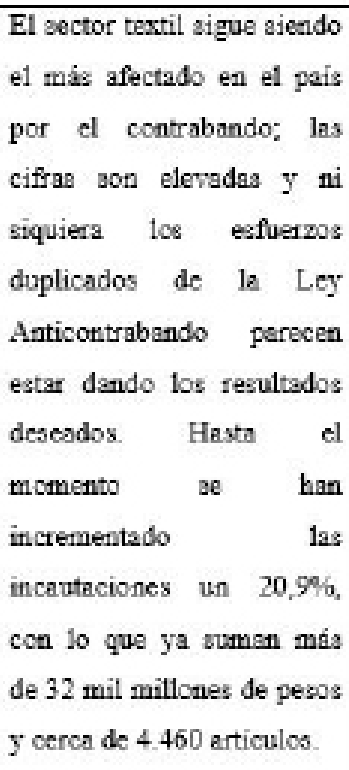 & $\begin{array}{l}\text { Colombia ha aumentado au } \\
\text { incidencia en la erisis textil ya } \\
\text { que se ba visto afectedo por el } \\
\text { microtrafico y el lavado de } \\
\text { disero que genera una gran } \\
\text { problemática que es el } \\
\text { contrabando de insumoe del } \\
\text { sector; ya que o hace una } \\
\text { competencia desleal en } \\
\text { comparación de precios de } \\
\text { productos aacionales } y \\
\text { productos ilegales. }\end{array}$ \\
\hline $\begin{array}{l}\text { ¿Por que marcha hoy el sector } \\
\text { textil en Colombia? } \\
\text { Econemia.3 Oct 2017.Diego } \\
\text { Ojeda. El Espectador. }\end{array}$ & $\begin{array}{l}\text { Le movilización, liderada } \\
\text { por empreasrios en eate } \\
\text { sector, tiene como objetivo } \\
\text { manifestar la defense del } \\
\text { empleo, la sostenibilidad } \\
\text { empresarial y la generación } \\
\text { de condiciones de equidad. }\end{array}$ & $\begin{array}{l}\text { los empresarios colombienos yo } \\
\text { eatin canados de la } \\
\text { competencia desleal contra la } \\
\text { importaciones de hocia ya que } \\
\text { no pueden aer competitivos por } \\
\text { sus bajos precios, con esto se ha } \\
\text { generado un gran desempleo y } \\
\text { una criais económica que no ha } \\
\text { podido dejar avanzar a la } \\
\text { incustria textil. }\end{array}$ \\
\hline Sector textil-confeccion en & Une demanda decreciente, & Le industria textil y 100 \\
\hline $\begin{array}{l}\text { jaque, ¿cuál es el futuro? } \\
\text { INDUSTRIA.8/31/2017. } \\
\text { DINERO. }\end{array}$ & $\begin{array}{l}\text { altos inventarios y el } \\
\text { permanente ingreso al pais } \\
\text { de productos a precios muy } \\
\text { bajos conforman la pesada } \\
\text { mercla que tiene a la } \\
\text { industria textil y de la } \\
\text { confección en jaque ¿Cuzi } \\
\text { es el futuro? }\end{array}$ & $\begin{array}{l}\text { empresarios cocno lo son Arturo } \\
\text { calle y fabricato frente a eata } \\
\text { crisis textil tan grave las únicas } \\
\text { alternativas que pueden generar } \\
\text { es frenar la producción lo que } \\
\text { genera desempleo y aumentar } \\
\text { carga labocar ya que no pueden } \\
\text { oontratar mas empleodos: esto } \\
\text { genera una economia estancada } \\
\text { para el pais. }\end{array}$ \\
\hline
\end{tabular}

Fuente: El investigador 


\section{0}

\section{Recomendaciones}

Con la información que se ha generado e investigado se puede aportar primero que todo el gobierno debe acoger al sector textil generando alternativas o soluciones que prioricen el producto nacional producido y no al de importación ni de contrabando dando proyectos a largo plazo y no a corto generando una estabilidad continua y no momentánea ; aun así tiene que ir de la mano de los empresarios textiles generando iniciativa y seguridad para poder seguir y ver un futuro próspero para poder salir del estancamiento económico que se ha generado por el deterioro del sector.

Lo importante es ver más allá del sector nacional y ver un panorama internacional como lo podemos abarcar y estudiar que él tiene un cambio continuo pero así debemos remover obstáculos para generar mayor competitividad para mantener una estabilidad.

\section{Conclusiones}

Con el panorama y análisis de sector textil se pudo que Colombia cuenta con la mano de obra, infraestructura, cultura y recursos de calidad de producción; pero aun así se deben plantear modelos y estrategias para poder exaltar cada uno de estas cualidades. El panorama de importaciones es grave frente al nacional ya que el nacional solo es el del $10 \%$ exportable y de un $40 \%$ importable por la industria asiática siendo esta un fenómeno que ha abarcado economías y las afecta de manera directa por cuanto su mano de obra es la más económica del mundo y esto incide en los precios de la producción de sus productos; lo cual genera un estancamiento y un desequilibrio económico; lo cual genera desempleo y pobreza para el país, generando una gran problemática de estancamiento de la economía.
Los empresarios del sector textil está buscando fortalecimiento y apoyo por parte del sector público como lo es el estado y el sector privado para fortalecerse en tecnología e innovación y lograr que los costos de producción sean cada vez menores y más rentables para esta industria y que a su vez sea un sector generador de valor agregado competitivo con las tendencias del mercado globalizado; ayudando a todos los problemas que ocasionan esta situación como lo son el desempleo y el desequilibrio económico.

\section{Referencias}

Achury y Bolívar (2009), Sector de la confección en Colombia. Bogotá: Universidad del rosario.

Bedoya, M. (1994). Ruta del contrabando. El tiempo. Recuperado de http://www.eltiempo. com/archivo/documento/MAM-249203

Caracol Cúcuta (2017) Textileros en Cúcuta saldrán a protestar. Recuperado de http:// caracol.com.co/emisora/2017/09/30/ cucuta/1506793532_568403.html

Conde A. (2009), La innovación como determinante de competitividad en la industria textil confección: el caso de corea y Colombia. Recuperado de: http://javeriana.edu.co/biblos/ tesis/economia/tesis56.pdf

Diario El Tiempo Los trasfondos de la 'guerra' con Panamá (2016), recuperado de: http://www. eltiempo.com/economia/sectores/aranceles-apanama-analisis-35169

Moreno V. (2006) Sector textil en Colombia: un análisis de las importaciones y exportaciones entre los años 2008 a 2014, Universidad Militar Nueva Granada.

Sectorial (2011) Historia del negocio textil, recuperado de: https://www.sectorial.co/ 
articulos-especiales/item/50352-historia-delnegocio-

Tamayo M. (2006), El proceso de la investigación científica, Editorial Limusa. México DF. 